\title{
COMPREENDENDO A MEDIAÇÃO DO TUTOR A DISTÂNCIA
}

\author{
Ana Vilma Tijiboy \\ tijigirl@ufrgs.br \\ UFRGS - Secretaria de Educação a Distância \\ Mára Lúcia Fernandes Carneiro \\ mara.carneiro@ufrgs.br \\ UFRGS - Instituto de Psicologia - Depto. de Psicologia Social e institucional \\ Lediane Raquel Woiciechoski \\ ledianeraquelw@yahoo.com.br \\ Eliane Almeida Pereira \\ elianealmeidapereira@yahoo.com.br
}

\begin{abstract}
RESUMO: A mediação que o tutor a distância exerce nos Ambientes Virtuais de Aprendizagem (AVAs) é de fundamental importância para o desempenho do aluno de Educação a Distância $(\mathrm{EaD})$ e elemento potencializador das relações de ensino e aprendizagem que envolvem os participantes de um curso nessa modalidade. Este artigo aborda possíveis formas da mediação na ferramenta Fórum de Discussão. Para isso, definiram-se categorias de mediação (Focalização, Expansão, Significação, Afetividade, Recompensa e Regulação). Duas outras categorias (Gerenciamento e Reflexão) foram criadas e definidas durante o estudo. Todas as categorias serviram de base para a análise de quatro tópicos do fórum de discussão da disciplina de Instrumentalização para o Ensino a Distância do curso de Planejamento e Gestão para o Desenvolvimento Rural (PLAGEDER) da UFRGS, com vistas a apoiar a atuação de tutores e demais interessados no assunto.
\end{abstract}

PALAVRAS-CHAVE: Mediação, tutor a distância, fórum de discussão.

ABSTRACT: The mediation tutors perform in Virtual Learning Environments (AVAS) is of fundamental importance for the achievement of students in Distance Education (DE). It can be an element that enhances the relationships of teaching and learning involving the participants in Distance Education. This article addresses possible forms of mediation in the Discussion Forum tool. To do so, the authors propose a set of categories of mediation (Focus, Expansion, Meaning, Affectivity, Reward and Regulation). Two other categories (Management and Reflection) were created and defined during the study. All categories served as the basis for the analysis of four topics of the forum for discussion of the discipline of Instrumentation for the Distance Education Course on Planning and Management for Rural Development (PLAGEDER) of the Federal University of Rio Grande do Sul (UFRGS) in order to support the work of tutors and others interested in the subject.

KEY WORDS: Mediation, tutor at distance, forum discussion. 


\section{INTRODUÇÃO}

No Brasil, a Educação a Distância foi regulamentada através da Lei de Diretrizes e Bases da Educação Nacional (LDB), no. 9.394, em 20 de dezembro de 1996. O Decreto $n^{\circ}$. 5.622, foi proposto em 2005 visando reformular e atualizar a legislação, definindo a educação a distância como uma modalidade educacional cuja mediação didáticopedagógica se dá pela utilização de meios e tecnologias de informação e comunicação e quando os sujeitos encontram-se em lugares ou tempos diversos.

Em se tratando de regulamentação da $\mathrm{EaD}$, existem ainda os Referenciais de Qualidade para Educação Superior a Distância (MEC, 2007), devem servir como referências norteadoras, subsidiando os atos legais do poder público no que se refere aos processos específicos de regulação, supervisão, organização dos sistemas e avaliação da modalidade de educação a distância no Brasil.

A Secretaria de Educação a Distância (SEED)' representa a intenção do governo em investir na educação a distância (e conseqüentemente nas novas tecnologias) como uma das estratégias para democratizar e elevar o padrão de qualidade da educação brasileira. Essa Secretaria desenvolve vários programas e projetos, dentre os mais recentes e importantes o Sistema Universidade Aberta do Brasil (UAB).

Segundo o MEC, o sistema UAB tem como prioridade a formação de professores para a Educação Básica, que para atingir este objetivo, realiza articulação entre instituições públicas de ensino superior, estados e municípios brasileiros. O grande desafio é promover, através da modalidade da educação a distância, acesso ao ensino superior para camadas da população que estão excluídas do processo educacional. Para ofertar um curso a distância pelo UAB, o município interessado deve montar um pólo presencial, ou seja, um espaço físico com infra-estrutura de laboratórios e bibliotecas, além do suporte de pessoal capacitado, o que inclui o apoio de tutores. A elaboração dos cursos é de responsabilidade das instituições públicas de ensino superior de todo país, que desenvolvem material didático e pedagógico.

Assim, dentro da proposta da UAB a Universidade Federal do Rio Grande do Sul (UFRGS) oferece através do Curso de Graduação Tecnológica na modalidade a distância em Planejamento e Gestão para o Desenvolvimento Rural (PLAGEDER) uma formação em nível superior com vistas a capacitar profissionais com perfil crítico e inovador para atuarem em questões relativas ao desenvolvimento, planejamento e gestão rural em nível local e regional. Além da capacidade de compreender e analisar a realidade local e regional, esse curso tem como objetivo formar profissionais capazes de assessorar as coletividades locais e regionais (públicas e privadas) na busca de soluções compatíveis com as necessidades e particularidades das sociedades nos espaços territoriais, bem como na formulação e assessoramento de políticas públicas. Por fim, busca proporcionar uma visão ampla e crítica da questão ambiental e suas articulações com o desenvolvimento e a gestão e o planejamento rural.

\section{CONTEXTUALIZANDO O ESTUDO}

Com base nos Referenciais de Qualidade para a Educação Superior a Distância (MEC, 2007), percebe-se que num curso EaD deve ser previsto um módulo introdutório, que leve o aluno ao conhecimento e domínio de habilidades básicas referentes à tecnologia utilizada e que também forneça uma visão geral da metodologia a ser empregada no curso. Nessa primeira fase, tenta-se dar/fornecer/promover os elementos necessários para que os 
alunos construam uma base de conhecimento tecnológico e pedagógico visando sua autonomia e participação ativa ao longo de todo o curso.

As disciplinas curriculares oferecidas pelo PLAGEDER foram desenvolvidas no Ambiente Virtual de Aprendizagem Moodle, sendo a primeira disciplina a de Instrumentalização para o Ensino a Distância. Tal disciplina abordou o seguinte conteúdo: Educação a distância e o modelo do PLAGEDER, Ambiente virtual de aprendizagem e seus recursos e o papel do aluno em cursos a distância (organização do estudo, disciplina, autonomia, etc.). Os dados coletados e analisados neste estudo provêm da observação dessa disciplina.

\section{EDUCAÇÃO A DISTÂNCIA E AS CARACTERÍSTICAS DO TUTOR}

Sobre a utilização da informática na educação de forma ampla, Valente (1999) sustenta que ela deve ser diversificada, interessante e desafiadora, não simplesmente transmissora de informação. O computador nessa proposta deve ser utilizado para enriquecer ambientes de aprendizagem e auxiliar o aprendiz no processo de construção de seu conhecimento. Por sua vez, cabe ao professor desafiar e incentivar seus alunos, de modo que eles possam aprender uns com os outros e com isso saber como se trabalha e se aprende em grupo.

$\mathrm{Na}$ educação a distância, a tarefa do professor torna-se ainda mais complexa, surgindo a necessidade de outros parceiros nesse processo de ensino e aprendizagem.

No modelo do UAB, os atores envolvidos no processo de ensino e aprendizagem a distância podem ser:

- Coordenadores: Desenvolvem atividades administrativas, coordenam os cursos ofertados pelas Instituições de Ensino Superior (IES) e gerenciam contatos entre MEC e pólos associados.

- Coordenadores de pólo: Coordenam a oferta do curso superior em seu pólo, a manutenção das instalações para atender seus alunos e estabelecem contato entre coordenadores UAB nas IES e MEC.

- Professores: Realizam/ministram aulas e disponibilizam material para estudo no espaço virtual. Fazem ainda visitas aos pólos em períodos de aulas presenciais, quando necessário.

- Alunos: Recebem os cursos a distância por meio de tecnologia informatizadas e utilizam o pólo de apoio presencial para realizarem seus estudos, pesquisas e assistirem as aulas presenciais previstas no currículo. estudos.

- Tutores (presencial e a distância): Estabelecem contato com alunos para apoio aos

Os Referenciais de Qualidade para a Educação Superior a Distância (MEC, 2007) consideraram que os professores vêem suas funções se expandirem em programas a distância, o que requer que sejam altamente qualificados. Por sua vez, neste contexto caracteriza-se o tutor como um agente fundamental nos processos de aprendizagem, avaliação e interação. Neste documento fica estabelecido que:

O tutor deve ser compreendido como um dos sujeitos que participa ativamente da prática pedagógica. Suas atividades desenvolvidas a distância e/ou presencialmente devem contribuir para o desenvolvimento dos processos de ensino e de aprendizagem e para o acompanhamento e avaliação do projeto pedagógico. (p. 21). 
O tutor a distância é o responsável pela mediação e pelo acompanhamento do aluno, oferecendo suporte em relação ao conteúdo ministrado na disciplina ou no curso. O tutor presencial, por sua vez, atua no pólo, servindo como elo de comunicação entre os estudantes e professores e executando alguns serviços administrativos e de suporte tecnológico. Neste estudo, foi abordado mais especificamente a atuação do tutor a distância, que também é responsável pela avaliação dos alunos.

Apesar da modalidade de EaD pressupor autonomia de aprendizagem por parte dos alunos e da maioria das orientações ser encontrada nos materiais didáticos elaborados pelo professor, observa-se que, na prática, o tutor a distância é fonte constante e permanente de informação e elo de comunicação entre professores e alunos. Assim, a atuação do tutor a distância torna-se interessante para o processo de ensino e aprendizagem virtual, o que justifica a busca de compreensão do papel desse tutor. Sua responsabilidade é grande não apenas pelo número elevado de alunos que atinge, mas também pela natureza avaliativa e pedagógica de suas ações junto aos alunos.

Segundo Niskier (1999, apud. PAULA et al, 2008), as ações do tutor na educação a distância correspondem ao ato de comentar os trabalhos realizados pelos alunos; corrigir avaliações; ajudá-los a compreender os materiais do curso, responder às questões; ajudar no planejamento dos trabalhos; organizar grupos de estudos; fornecer e atualizar informações; fornecer feedback aos coordenadores e servir de intermediário entre instituição e alunos, ou seja, deve envolver a função de "facilitador e mediador da aprendizagem, motivador, orientador e avaliador".

Segundo concepção do curso e de acordo com o Guia do Tutor a Distância do PLAGEDER (2007), o tutor a distância deve ser um especialista na área de conhecimento em que atuará e possuidor de domínio no uso dos recursos computacionais e Internet. Foi determinada uma carga horária semanal de 20 horas e o atendimento a turmas com cerca de 25-30 alunos. Na descrição de suas atividades, esperava-se do tutor a distância o acompanhamento e o desenvolvimento das atividades propostas pelo professor, verificando a participação e identificando os avanços e dificuldades no sentido de fornecer o máximo de subsídios aos alunos. Este tutor deve informar ao professor sobre o desenvolvimento do aluno e ser facilitador da interação dos sujeitos envolvidos por meio de recursos como: agenda, fórum, chat, e-mail e biblioteca, entre outros. Além disso, espera-se do tutor a distância que estimule a participação do grupo de alunos, respeitando as diferenças e estabelecendo uma relação de confiança e cordialidade.

As funções de tutoria destacadas acima condizem com as três dimensões dos saberes docentes na educação a distância ressaltadas por Belloni (2001) apud Paula et al (2008). A dimensão Pedagógica - corresponde a orientação, aconselhamento e tutoria. A Tecnológica - diz respeito à produção, avaliação, seleção e definição de estratégias de uso dos materiais pedagógicos. E a Didática - refere-se à formação específica e à necessidade de constante atualização profissional dos professores e tutores.

Podem-se destacar, então, como características imprescindíveis para um tutor, a capacidade de estabelecer relações de empatia com os envolvidos e o domínio das ferramentas tecnológicas e de comunicação.

\section{ESPAÇO DE INTERAÇÃO: FÓRUM DE DISCUSSÃO}

Os Referenciais de Qualidade para a Educação Superior a Distância (MEC, 2007) apontam o estudante como o centro do processo educacional. Enfatizam também que o sistema de tutoria deve ser apoiado em um ambiente computacional que promova interação, 
e que tal sistema deve atender as necessidades dos estudantes. Assim, ambos os aspectos devem ser norteadores na escolha do ambiente virtual de aprendizagem e na criação/caracterização da sala de aula virtual.

Os Ambientes Virtuais de Aprendizagem (AVAs), sistemas possíveis com o avanço das novas tecnologias de informação e comunicação para uso na educação, utilizam-se da Internet para seu funcionamento e alcance a lugares distantes. São ainda espaços, no sentido de representação de salas de aula, onde os alunos têm a oportunidade de interagir, aprender, trocar e produzir conhecimento. Espera-se que cada participante passe por uma etapa de experimentação e de apropriação das ferramentas de comunicação e interação que essas plataformas disponibilizam, e após essa etapa podem e devem refletir sobre os resultados obtidos.

A EaD requer, fundamentalmente, a utilização de tecnologias e ferramentas de comunicação que sejam capazes de mediar o diálogo entre os sujeitos envolvidos, durante o período de duração do curso. Assim, Almeida (2003) diz que a distância geográfica e o uso de diferentes mídias e recursos que os AVAs disponibilizam são características inerentes à EaD, mas "não são suficientes para definir a concepção educacional" de um curso.

Moore e Kearsley (2007) diz que os sistemas de aprendizado na Web -AVAs - "têm capacidade para comunicações não somente assíncronas e síncronas, também incluem recursos de gerenciamento e testes".

Sobre o gerenciamento dos recursos dos ambientes de aprendizagem (AVAs), Almeida (2003) diz que estes propiciam a gestão estratégica da comunicação e da participação dos alunos por meio do registro das produções, interações e caminhos percorridos, a gestão do apoio e orientação dos formadores e da avaliação.

Cabe alertar que apesar da variedade de recursos de interação ou ferramentas que um ambiente virtual de aprendizagem disponha, cabe à equipe docente avaliar continuamente o processo de interação, devendo em diversos momentos promover a cooperação, a reflexão, etc, realizando mediação entre aluno, ambiente, ferramentas e conhecimento.

O fórum de discussão é uma das ferramentas comumente encontrada nos ambientes virtuais de aprendizagem. Caracteriza-se por permitir interação entre todos os envolvidos do curso, seja entre professores e alunos e/ou alunos entre si. Segundo Oliveira e Filho (2006), é um espaço onde as possibilidades de intervenção, autoria e produção de sentido se encontram. Propicia também uma modalidade de conversação assíncrona e intencional, com a finalidade pedagógica da construção e reconstrução de saberes. É ainda um espaço virtual onde se registram as intervenções dos participantes de uma discussão durante um determinado tempo. Isto é, mantém registrado sob a forma de intervenção ou postagem as comunicações escritas dos integrantes do curso.

Em se tratando de mediação e acompanhamento mais especificamente no fórum de discussão, pode-se dizer que a função principal do tutor é orientar a aprendizagem dos alunos, através de intervenções que possibilitem debates e discussões e onde todos possam se relacionar colaborativamente em busca da construção do conhecimento.

\section{A MEDIAÇÃo}

Refletindo sobre aprendizagem e educação a distância, faz-se necessário considerar a questão da mediação pedagógica. Segundo Masetto (2000), o conceito de mediação vai além da ação pedagógica, incluindo também os materiais utilizados e os demais alunos envolvidos na aprendizagem. 
O processo de mediação pode ser explicado segundo a teoria de Vygotsky (1984), na medida em que um estímulo auxiliar possui a função específica de uma ação reversa, ou seja, é uma ação que ocorre quando uma intervenção humana deixa de ser direta passando a ser mediada por algum elemento. No caso da mediação pedagógica, essa intervenção é intencional e sistematizada, assumindo um papel importante no processo de apropriação do conhecimento por parte do aluno. Ainda, segundo Vygotsky (1984), pode-se dizer que o homem é um ser social, constituído a partir das relações sociais que estabelece com o outro e com o meio, sendo ao mesmo tempo produto e produtor destas relações num processo sócio-histórico. Assim, o aprendizado é resultado deste processo de relações sociais, onde o sujeito se apropria das estruturas lingüísticas e cognitivas do grupo a que pertence. Esse processo interno de reconstrução é chamado de internalização, ou seja, é onde a atividade externa se modifica em processos internos no sujeito.

Assim, em situações de EaD, pode-se dizer que compete ao tutor a distância (além do professor) mediar o processo de apropriação/construção do conhecimento partindo do nível de conhecimento real, aquilo que o aluno previamente tem conhecimento e que já demonstrou através das ferramentas de interação (uma das quais é o fórum de discussão), para um nível de desenvolvimento potencial, que é aquilo que este será capaz de aprender.

Para Santos (2008) falar desse processo de mediação, segundo Vygotsky, justificase pela necessidade humana de interação social no processo de ensino, pois é por meio da aprendizagem nas relações com os outros que se constroem os conhecimentos que permitem o desenvolvimento mental do aluno. Para este autor, o modelo de aprendizagem que embasa as necessidades da sociedade atual, deve ser dinâmico, levando em conta os saberes e as interconexões mentais do aluno. Para que este aluno seja capaz de reconstruir seu próprio conhecimento e formar novos conceitos sobre o mundo, agindo e reagindo diante da realidade que o cerca.

No conceito de educação a distância, todos os sujeitos envolvidos são responsáveis pelo seu próprio desenvolvimento, considerando sua capacidade de formação independente e autônoma e ainda através de um processo interativo de troca de saberes, mas a mediação dos agentes envolvidos precisa ser bem orientada e os critérios de avaliação bem definidos. Dessa forma, o uso das tecnologias na educação deve estar apoiado numa filosofia de aprendizagem que proporcione aos estudantes oportunidades de interação e principalmente, a construção do conhecimento. (MEC, 2007).

As funções que o tutor a distância desempenha podem a primeira vista parecer fácil. Estas seriam: fazer mediações e interlocuções através das ferramentas do ambiente/plataforma de ensino utilizado no curso, manter ativa a participação dos alunos e "prestar contas" ao professor. Em teoria, qualquer pessoa com formação superior ou experiência no magistério seria capaz de conduzir uma aula/disciplina a distância. Mas como será que isso acontece na prática?

\section{CONTRIBUIÇÃO DO ESTUDO - CATEGORIAS DA MEDIAÇÃO}

A mediação pedagógica é elemento fundamental na ação de tutores, ocorrendo em contextos educacionais de EaD. Entendê-la poderá torná-la mais consciente e proposital, contribuindo para a melhoria do ensino e da aprendizagem.

Em se tratando de componentes de mediação, cabe destacar as contribuições de Vectore (2006) enfatizando o comportamento do mediador a partir da uma Escala de Comportamentos Mediacionais de Educadores Infantis, sendo eles: Focalização, Expansão, Afetividade ou Significação, Recompensa e Regulação do Comportamento. Esses 
componentes de mediação serviram de base para a análise de dados neste estudo. Tais conceitos foram adaptados para a mediação do tutor a distância.

A indagação de pesquisa que orientou o estudo foi: Que características compõem a mediação do tutor a distância no fórum de discussão?

Visando clareza na análise dos dados coletados seguem as definições de termos. Nesse estudo, entendeu-se como:

- Tutor a distância: Pessoa que trabalha em cursos a distância, através de ambientes virtuais de aprendizagem, subordinada ao professor da disciplina/curso. Realiza a mediação pedagógica através das ferramentas de interação do ambiente, neste caso, no âmbito do curso PLAGEDER.

- Fórum de discussão: Ferramenta/recurso/espaço disponível no ambiente virtual de aprendizagem, onde os sujeitos se comunicam através de mensagens de maneira escrita e de forma assíncrona. Todos os sujeitos envolvidos no curso podem criar novos tópicos para discussão, embora a orientação é que os tópicos sejam criados pelo tutor a distância.

- Mediação: Ação desempenhada no acompanhamento da disciplina/curso na modalidade a distância. Ações de intervenção do tutor/professor no processo de ensino e aprendizagem do aluno. As categorias de mediação criadas com base em Vectore (2006) usadas para análise da mediação do tutor, foram:

Focalização: Atitude do mediador direcionando o foco do aluno para a tarefa proposta. Explicações, demonstrações, exemplificações, perguntas e frases que chamem atenção do aluno para retornar ao objetivo.

Expansão: Ações que visem propiciar uma expansão do pensamento do aluno através de explicações e comparações emitidas pelo mediador que auxiliem a compreensão de conteúdo e o estabelecimento de novas relações, indo além do contexto de sala de aula. O mediador dá exemplos concretos para explicação dos conteúdos. Aproveita qualquer comportamento do aluno para reforçar o conteúdo.

Significação: Manifestações do mediador na busca de auxiliar o aluno a compreender o significado dos conteúdos e/ou atividades.

Afetividade: Manifestações do mediador que expressem seu envolvimento afetivo com o aluno, através do incentivo a participação e a iniciativa do mesmo. Elogia as ações por ele executadas. Reconhece o empenho do aluno. Cria um clima harmonioso e amigável no ambiente. Há compreensão e empatia sobre a situação do aluno.

Recompensa: Manifestações do mediador para com o aluno expressando sua satisfação pelo empenho deste, explicando o motivo do elogio.

Regulação: Intervenções do mediador no sentido de auxiliar o aluno a organizar sua ação, implicando em planejamento para alcançar o objetivo.

Gerenciamento: Ações do mediador que busquem orientar o aluno sobre como proceder, abrangendo comportamentos, atitudes, procedimentos específicos da modalidade de EaD.

Reflexão: Questionamentos e perguntas do tutor ao aluno, visando a solução de um problema. Implica necessariamente uma ação consciente ou intencional do mediador em provocar o raciocínio critico do aluno. $\mathrm{O}$ mediador não fornece respostas, mas instiga a busca dessas pelo próprio aluno.

\section{A ANÁLISE DOS DADOS}

Foram analisados quatro tópicos do fórum de discussão da disciplina de Instrumentalização para o Ensino a Distância do curso PLAGEDER. Cada tópico analisado 
corresponde à mediação de um tutor a distância. Assim, puderam-se analisar as características de mediação do tutor sob o enfoque de quatro sujeitos de pesquisa, denominados no corpo textual desse estudo como Tutor A, B, C e D.

As intervenções encontradas no fórum de discussão de cada tutor observado foram classificadas levando em consideração os componentes da mediação anteriormente descritos. Para compor um perfil individualizado por tutor, foram destacadas as duas características ou componentes que mais se repetiram na conduta ou mediação destes agentes.

No final, todas as intervenções foram quantificadas num gráfico (Gráfico demonstrativo dos componentes da mediação), representando as características da mediação encontradas neste grupo de tutores, ou seja, no âmbito do curso PLAGEDER.

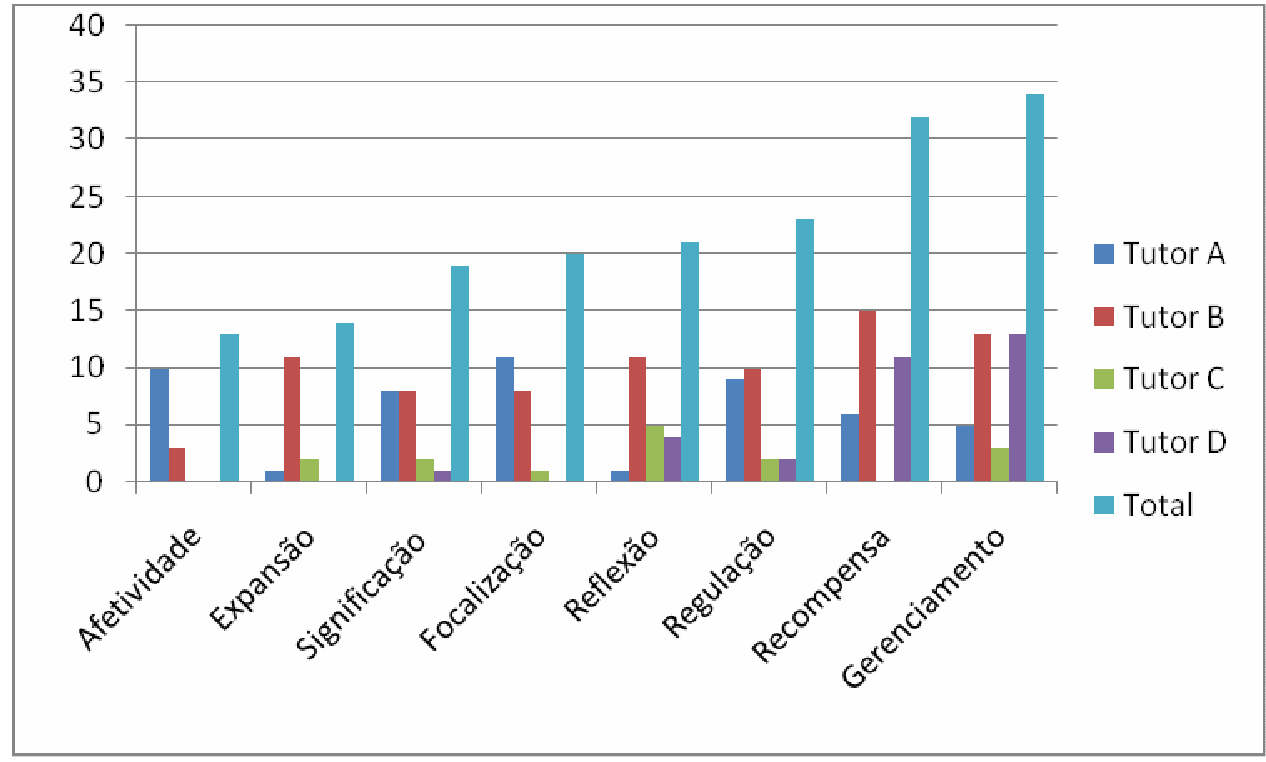

Gráfico demonstrativo dos componentes da mediação

Analisando o gráfico podemos identificar que as características da mediação encontradas seguindo a ordem da direita para a esquerda foram as de: Gerenciamento, Recompensa, Regulação, Reflexão, Focalização, Significação, Expansão e Afetividade.

Observou-se que a característica que mais se repetiu foi a de Gerenciamento. Convém salientar que esta categoria não constava nos componentes de mediação pedagógica proposta por Vectore (2006). Ela surgiu a partir da análise inicial e geral das mediações/intervenções dos tutores. Definimos a característica de Gerenciamento como "Ações do mediador que busquem orientar o aluno sobre como proceder, abrangendo comportamentos, atitudes, procedimentos específicos da modalidade de EaD."

Exemplos ou evidências de mediação do tipo Gerenciamento:

- "qualquer dúvida pode ser encaminhada para o tutor"

- "por acaso você enviou uma mensagem para colocar a tua dúvida?”

Podemos inferir que esta característica de mediação tende a aparecer nas disciplinas iniciais de cursos a distância. Poderíamos ainda observar ou consultar tutores de outras disciplinas e perceber que possivelmente ela se manteria. Muito provavelmente essa característica teve maior incidência devido à natureza da disciplina que visava instrumentalizar os alunos no ensino a distancia. 
Podemos inferir também que em outras disciplinas no decorrer do curso outras características de mediação teriam maior incidência uma vez que os alunos já estariam familiarizados com a tecnologia e formas de proceder em ambientes virtuais de aprendizagem.

A característica da Reflexão, da mesma forma, não constava na proposta de Vectore. Ela também surgiu na etapa inicial e geral de analise das mediações dos tutores. Sua definição é "Questionamentos e perguntas do tutor ao aluno, visando a solução de um problema. Implica necessariamente uma ação consciente ou intencional do mediador em provocar o raciocínio critico do aluno. $\mathrm{O}$ mediador não fornece respostas, mas instiga a busca dessas pelo próprio aluno". Esta característica foi encontrada nas intervenções de todos os tutores, sugerindo que ela é importante que ocorra para provocar que o aluno busque suas próprias respostas.

Exemplos ou evidências de mediação do tipo Reflexão:

- "porque você não consegue sentir-se a vontade?"

- "quer dizer que você está fazendo um curso sem motivação?”

Outra constatação foi que cada tutor possui diferentes características de mediação. A identificação destas características poderia ser levada em consideração no momento de sua seleção para o curso/disciplina, uma vez que cada instituição define o perfil que espera da intervenção/mediação deste agente.

\section{CONCLUSÃO}

Percebeu-se, a partir das orientações do MEC, que o modelo de avaliação em EaD deve ser contínuo, e para tal, devem ser articulados mecanismos que promovam o permanente acompanhamento dos alunos. Nesse sentido, foram focados neste estudo, tanto o tutor a distância quanto a ferramenta fórum de discussão. Acredita-se que se a mediação pedagógica for orientada e realizada de maneira adequada e o fórum usado como instrumento de acompanhamento e de resposta aos questionamentos dos alunos, a interação que aí ocorre pode constituir-se em elemento potencializador das relações de ensino e aprendizagem que envolve os participantes de um curso.

Acredita-se que debates sobre a educação a distancia no Brasil são importantes, sobretudo porque nos fazem refletir amplamente sobre nossas compreensões de educação, de sociedade e de mundo. Com isso, sugere-se a necessidade de novas compreensões e ressignificações para o processo de ensino e aprendizagem.

O presente estudo buscou verificar características que podem compor a mediação do tutor a distância no fórum de discussão. Neste processo acredita-se que uma das contribuições mais importantes deste estudo foi a constatação, criação e definição das categorias de mediação de Gerenciamento e de Reflexão.

Finalmente, sugere-se e espera-se que outros estudos dêem seqüência contribuindo para melhor entendimento das mediações pedagógicas em ambientes virtuais de aprendizagem.

\section{REFERÊNCIAS}

ALMEIDA, Maria Elizabeth Bianconcini de. Educação a distância na internet: abordagens e contribuições dos ambientes digitais de aprendizagem (2003). Disponível em: <http://www.scielo.br/pdf/ep/v29n2/a10v29n2.pdf>. Acesso em Maio de 2008. 
MASETTO, Marcos. Mediação pedagógica e uso da tecnologia. In: MORAN, José Manuel, MASETTO, Marcos, BEHRENS, Marialda. Novas tecnologias e mediação pedagógica. Campinas: Editora Papirus, 2000.

MEC - Referenciais de Qualidade na EAD. 2007. Disponível no site: $<$ http://portal.mec.gov.br/seed/arquivos/pdf/legislacao/refead1.pdf>. Acessado em Novembro de 2008.

MOORE, M. e KEARSLEY, G. Educação a Distância: uma visão integrada. São Paulo: Thomson Learning, 2007.

OLIVEIRA, Sheila da Costa, FILHO, Gentil José de Lucena. Animação de fóruns virtuais de discussão - novo caminho para a aprendizagem em EAD via web. RENOTE, V. 4, $\mathrm{N}^{\mathrm{o}} 2$, Dezembro de 2006. Disponível em: http://www.cinted.ufrgs.br/renote/dez2006/artigosrenote/25159.pdf>. Acessado em Setembro de 2008.

PAULA, Alessandra de Paula et al. Educação a distância: proposta para avaliação do desempenho do tutor na educação a distância. 2008. Disponível em: $<$ http://www.abed.org.br/congresso2008/tc/512200833121AM.pdf>. Acesso em Outubro 2008.

SANTOS, Júlio César Furtados dos. Aprendizagem Significativa: modalidades de aprendizagem e o papel do professor. Porto Alegre: Mediação, 2008. 96 p.

VALENTE, José Armando. O computador na sociedade do conhecimento. Campinas: UNICAMP/NIED, 1999. 156 p.

VECTORE, Célia; ALVARENGA, Valesca Cristina; GOMIDE, Junior Sinésio. Construção e validação de uma escala de comportamentos mediacionais de educadores infantis. Psicologia Escolar e Educacional, V. 10, p. 68. 2006.

VYGOTSKY, Lev Semenovich (1984). A Formação Social sa Mente: O Desenvolvimento dos Processos Psicológicos Superiores. São Paulo: Martins Fontes, 2002. 191 p. 